\title{
El efecto de las técnicas en los datos: el caso de la anticoncepción
}

The effect of techniques on data: the case of contraception

\author{
Carmuca Gómez Bueno \\ Universidad de Granada. Grupo de investigación SEJ-339 \\ cgomez@ugr.es (ESPAÑA)
}

Recibido: 15.032012

Aceptado: 20.11.2012

\section{RESUMEN}

A partir de la revisión de encuestas sobre el uso de métodos anticonceptivos, tanto en el ámbito internacional como el nacional, realizamos un análisis comparativo. A continuación, contrastamos esos datos con los obtenidos a través de técnicas cualitativas: entrevistas y grupos de discusión, en el ámbito andaluz. Esta acotación en el espacio se corresponde con otra realizada sobre los métodos anticonceptivos, al centrarnos en un método concreto, el coitus interruptus. Observamos discrepancias en la prevalencia anticonceptiva aportada por diferentes encuestas atribuibles, en parte, al efecto de las técnicas y, en parte, a las características del objeto que se pretende medir. La definición de la base poblacional, la formulación de la pregunta (remitiendo a uno u otro período de tiempo) y el modo de aplicación, son los aspectos técnicos que más variaciones introducen. Respecto al objeto es la poca estabilidad de algunas prácticas anticonceptivas lo que más entorpece su medición. Las diferencias entre la información producida con técnicas cuantitativas y cualitativas muestran tanto la complejidad del objeto de estudio y su medición (las numerosas precisiones a tener en cuanta al comparar e interpretar los datos) como la complementariedad de las técnicas.

\section{PALABRAS CLAVE}

Técnicas cuantitativas y cualitativas de investigación social; análisis comparativo de datos de encuestas; prevalencia anticonceptiva; uso de métodos anticonceptivos; coitus interruptus o marcha atrás. 


\begin{abstract}
Through the examination of surveys we carried out a comparative analysis on the use of contraceptive methods in national and international settings. We then contrasted these data with those obtained through qualitative techniques: interviews and discussion groups, in the context of Andalusia (Spain). This geographical restriction corresponded to another observation we conducted, focusing on one specific method: coitus interruptus. We found discrepancies in the prevalence of contraceptive methods reported in different surveys, attributable in part to the effect of the data-gathering techniques employed, and in part to the characteristics of the object which we intended to evaluate. The definition of the population, the mode of data collection, as well as the drafting of the questions, which referred to different periods of time, were the aspects which introduced most variations. As regards the object of our study, the low stability of some contraceptive practices tended to hamper their measurement. Differences encountered between the information obtained through quantitative or qualitative procedures reveal, on the one hand, the complexity of the object of our study and its appraisal (involving the numerous variables to be taken into account when comparing and interpreting data), and on the other, the complementary of the data-gathering techniques.
\end{abstract}

\title{
KEYWORDS
}

Quantitative and qualitative techniques of social research; comparative analysis of surveys; contraceptive prevalence; use of contraceptive methods; coitus interruptus or withdrawal.

\section{INTRODUCCIÓN}

Periódicamente se publican datos sobre prevalencia anticonceptiva en el ámbito internacional. Son datos válidos y fiables producidos por las oficinas de estadística de cada país pero ¿hasta dónde son pertinentes las, siempre ilustrativas, comparaciones internacionales?, ¿cómo se construyen esos datos?, ¿qué aportan y qué ocultan los datos sobre temas tan complejos, sensibles e íntimos producidos a través de encuesta?, ¿qué información adicional puede captarse a través de las técnicas cualitativas? Para avanzar en la respuesta a estas cuestiones partimos de los datos sobre prevalencia anticonceptiva en determinados países occidentales centrándonos, a continuación, en un método tradicional: la marcha atrás, y, en un ámbito territorial, el español. Tras revisar los procedimientos de construcción de los datos sobre anticoncepción en España, 
comparamos los resultados alcanzados con los producidos a través de técnicas cualitativas $^{1}$ en Andalucía.

\section{ANÁLISIS COMPARATIVO DE LAS PRÁCTICAS ANTICONCEPTIVAS EN DIFERENTES PAÍSES OCCIDENTALES}

Naciones Unidas (N.U.,2011) nos informa sobre la prevalencia anticonceptiva en 193 países o áreas del mundo, calculada a partir del número de mujeres en edad reproductiva (15-49 años) casadas o en unión que utilizan algún método anticonceptivo dividido por el número total de mujeres de ese grupo de edad y situación de convivencia y multiplicado por 100. Nos advierte, asimismo, de las limitaciones y peculiaridades de cada encuesta y de sus posibles repercusiones sobre la comparabilidad de los datos. Según esta fuente, la prevalencia anticonceptiva en Europa es del 72,6\%, oscilando entre el 63,8\% de Europa del Sur y el 80,1\% de Europa del Norte (N.U. 2011, Regional Averages). No obstante, como muestra la tabla siguiente, se observan grandes variaciones en el tipo de anticonceptivos empleados en los diferentes países:

Tabla 1. Prevalencia anticonceptiva en diferentes países (porcentajes)

\begin{tabular}{|c|c|c|c|c|c|c|c|}
\hline & España & $\begin{array}{l}\text { Italia } \\
\text { (a) }\end{array}$ & $\begin{array}{l}\text { Noruega } \\
\text { (b) }\end{array}$ & $\begin{array}{l}\text { Suecia } \\
\text { (a) }\end{array}$ & Francia & $\begin{array}{l}\text { EE.UU. } \\
\text { (c) }\end{array}$ & $\begin{array}{l}\text { R.U. } \\
\text { (c) (d) }\end{array}$ \\
\hline AÑO & 2006 & $1995-96$ & 2005 & 1996 & $2004-5$ & 2006-8 & 2008-9 \\
\hline $\begin{array}{l}\text { Prevalencia } \\
\text { anticonceptiva \% }\end{array}$ & 65,7 & 62,7 & 88,4 & 75,2 & 76,6 & 78,6 & 84 \\
\hline $\begin{array}{l}\text { Prev. métodos } \\
\text { modernos }\end{array}$ & 62,3 & 40,6 & 82,2 & 64,8 & 74,8 & 73 & 84 \\
\hline $\begin{array}{c}\text { Esterilización } \\
\text { - femenina } \\
\text { - masculina }\end{array}$ & $\begin{array}{l}5,6 \\
7,9\end{array}$ & $\begin{array}{l}6,0 \\
0,1\end{array}$ & $\begin{array}{l}7,7 \\
-\end{array}$ & - & - & $\begin{array}{l}23,6 \\
12,7\end{array}$ & $\begin{array}{r}8,0 \\
21,0\end{array}$ \\
\hline Píldora & 17,2 & 14,2 & 31,0 & 27,4 & 41,5 & 16,3 & 28,0 \\
\hline Inyectables & 0,2 & 0,1 & - & - & - & 1,4 & 2,0 \\
\hline DIU & 6,4 & 5,8 & 23,3 & 16,2 & 22,7 & 5,3 & 10,0 \\
\hline Preservativo & 24,8 & 14,2 & 12,8 & 16,4 & 6,8 & 11,7 & 27,0 \\
\hline
\end{tabular}

${ }^{1}$ Utilizamos los discursos producidos en una investigación realizada a instancia y con financiación de la Consejería de Salud de la Junta de Andalucía. Ver Gómez Bueno, Carmuca (dir), Bretin, Hélène y Puente Navas, Rocío (2011a y 2011b). 


\begin{tabular}{|c|c|c|c|c|c|c|c|}
\hline & España & $\begin{array}{l}\text { Italia } \\
\text { (a) }\end{array}$ & $\begin{array}{l}\text { Noruega } \\
\text { (b) }\end{array}$ & $\begin{array}{l}\text { Suecia } \\
\text { (a) }\end{array}$ & Francia & $\begin{array}{l}\text { EE.UU. } \\
\text { (c) }\end{array}$ & $\begin{array}{l}\text { R.U. } \\
\text { (c) (d) }\end{array}$ \\
\hline AÑO & 2006 & $1995-96$ & 2005 & 1996 & $2004-5$ & $2006-8$ & $2008-9$ \\
\hline Métodos de barrera & 0,2 & 0,2 & 4,1 & 0,7 & 0,6 & 一 & 1,0 \\
\hline Implantes y otros & 0,0 & 0,0 & 3,3 & 4,1 & 3,2 & 2,0 & 3,0 \\
\hline $\begin{array}{l}\text { Prev. métodos } \\
\text { tradicionales \% }\end{array}$ & 3,5 & 22,1 & 6,3 & 10,4 & 1,7 & 5,6 & 8,0 \\
\hline Ritmo & 0,3 & 3,7 & - & 2,6 & 0,3 & 1,2 & 2,0 \\
\hline Coitus interruptus & 1,9 & 18,2 & - & 7,8 & 1,0 & 4,5 & 6,0 \\
\hline Otras & 1,3 & 0,2 & - & 0,0 & 0,4 & 0,0 & 0,0 \\
\hline Población & $15-49$ & $20-49$ & $20-44$ & $18-44$ & $15-49$ & $15-44$ & $16-49$ \\
\hline
\end{tabular}

Fuente: World Contraceptive Use 2011- United Nations • Department of Economic and Social Affairs • Population Division.

http://www.un.org/esa/population/publications/contraceptive2011/contraceptive2011.htm a: incluye hombres en la muestra; b: mujeres sexualmente activas los tres meses anteriores a la encuesta, incluye solteras con hijos; c: incluye anticoncepción de urgencia ; d: las cifras por método no suman el total debido al uso combinado de algunos de ellos.

A grandes rasgos, en todos los países considerados es mayoritario el uso de métodos modernos. En Europa, el descenso del uso de métodos tradicionales es continuado desde los años 80. Aunque, llama la atención la elevada presencia de estos últimos en Italia, donde el coitus interruptus es practicado por el 18,2\%, así como su discreta presencia en España: 1,9\%. Al analizar cada uno de los métodos anticonceptivos, encontramos que: la esterilización es el método más frecuente en Estados Unidos y Reino Unido. La píldora ocupa el primer lugar en Francia, Noruega y Suecia, mientras que el preservativo lo hace en España. Entre los países con mayor prevalencia anticonceptiva, los métodos más extendidos son la píldora, el DIU y/o la esterilización, y, entre aquellos con menor prevalencia, lo son el preservativo (España) y la marcha atrás (Italia).

Es frecuente atender a los resultados sin cuestionar los procesos de producción de los datos, especialmente cuando son aportados por grandes organismos. Pero, ¿son éstos directamente comparables o existen limitaciones a la comparabilidad interterritorial y/o longitudinal? Sólo con fijarnos en la información contenida en la tabla anterior vemos que:

1) El rango de edad de la población encuestada introduce diferencias que contaminan los resultados. Si España y Francia utilizan el rango de edad más 
amplio, Noruega y Suecia hacen lo contrario. Estos, al excluir el grupo de más edad, prescinden probablemente de las más expuestas al riesgo; las que hacen un uso menos regular de los anticonceptivos ${ }^{2}$, aumentado así la tasa.

2) La fecha de producción de los datos considerados varía hasta en 13 años. N.U. publica los datos más actuales enviados desde las diferentes oficinas de estadística. En 2011 Italia continúa aportando datos de 1995-96 al igual que Suecia, año en que la marcha atrás era practicada por el 18,2 y el 7,8\% en dichos países. Luego, las tasas más elevadas de métodos tradicionales corresponden a los países que aportan la información más antigua.

Por tanto, la información contenida en la tabla 1 nos permite identificar dos sesgos relevantes, introducidos por las variaciones en el rango de edad y la fecha de producción de los datos. Con esas dos consideraciones metodológicas ganamos en precisión al interpretar las comparaciones. Ahora bien, para garantizar la comparabilidad de los datos deberíamos estudiar también los objetivos, el diseño de la encuesta, el modo de aplicación, la base poblacional (sexo, situación de convivencia, actividad sexual, país de origen), los tipos y tamaños muestrales, las tasas de respuesta y los cuestionarios: formulación y ordenación de las preguntas: filtros, formatos, categorías de respuesta, preguntas de control...

De modo que aumentaríamos la comparabilidad si aplicáramos simultáneamente el mismo cuestionario, en diferentes países (aunque ello no garantice la homogeneidad en la interpretación de las preguntas; la existencia de un marco de referencia común). En 1995-96, la división de población de Naciones Unidas, lanzó la Fertility and Family Survey (FFS) en 23 países ${ }^{3}$, entre ellos Italia, Francia y España. En Italia la muestra fue de 4824 mujeres y 1206 hombres. El modo de aplicación del cuestionario fue con encuestadoras entrenadas. En Francia, la encuesta fue realizada por el INSEE en el contexto de la encuesta de empleo. La muestra estuvo formada por 2934 mujeres y 1928 hombres. El modo de aplicación fue escrito (duración media de 32 minutos), la tasa de respuesta baja y, el cuestionario «no fue idéntico al modelo». En España, la realización corrió a cargo del CIS que utilizó su diseño muestral estándar, quedando formada la muestra por 4812 mujeres y 1991 hombres. El cuestionario fue aplicado por encuestadores entrenados, del mismo sexo que el encuestado-a.

La pregunta sobre el uso de anticonceptivos se realizó a mujeres fértiles, no embarazadas, de 20 a 49 años y sexualmente activas (habían mantenido relaciones sexuales en el mes de referencia) o sus parejas. La FFS utilizó una

${ }^{2}$ En España, existe una fuerte asociación entre la tasa de mujeres en edad fértil, con pareja en casa, que no usan anticonceptivos y la edad. Las proporciones pasan del 13\% para las de 15-19 años al 38\% para las mujeres de 45-49 años [media 23\%] (Delgado et al, 2007:120).

${ }^{3} \mathrm{http} / / / \mathrm{www}$. unece.org/pau/ffs/ffstab.html 
pregunta abierta, formato que suele recoger las respuestas más legítimas. La pregunta fue:

$515^{*}$ ¿Qué método anticonceptivo o combinación de métodos utilizaron usted o su pareja en las últimas cuatro semanas? ${ }^{4}$

\section{Método A}

\section{Método B si se usó en combinación}

De los tres países seleccionados, descartamos Francia por las variaciones introducidas en el cuestionario. España arrojó la tasa de uso de anticonceptivos del $81,1 \%$, siendo la marcha atrás utilizada por el 11,4\%. En Italia el $62,7 \%$ usaron algún método y en el 18,2\% de los casos ese método fue la marcha atrás. Se mantiene la primacía de Italia en el recurso a la marcha atrás pero matizada, dado que las diferencias con España se reducen considerablemente al equiparar el diseño y el año de producción de los datos.

Si adoptamos una perspectiva longitudinal observamos que en España los datos de encuesta sobre prácticas anticonceptivas reflejan fuertes cambios entre una y otra aplicación, y que las tendencias de Francia y España sólo coinciden en el descenso registrado en 2006 respecto al período inmediatamente anterior. Para Italia no contamos con datos cuantitativos oficiales actualizados ${ }^{5}$, sin embargo, recientes investigaciones cualitativas analizan el uso de la marcha atrás.

En la FFS, la precisión en la definición de la base poblacional (no embarazadas sexualmente activas y nacionales) y el formato de la pregunta contribuyen al aumento de la tasa. Dado lo novedoso de la inclusión de los hombres en la muestra, cabe la hipótesis de que con ellos el efecto de legitimidad de la situación de encuesta se agudice, aumentando las respuestas consideradas «apropiadas» y, por tanto, la prevalencia. Veamos que precisiones nos aporta el análisis pormenorizado del caso español.

\section{LAS ENCUESTAS NACIONALES SOBRE PRÁCTICAS ANTICONCEPTIVAS}

Como se recordará, los anticonceptivos estuvieron prohibidos en España entre 1941 y 1978. Fue en octubre de 1978 cuando se despenalizaron el uso de los métodos anticonceptivos reversibles y, en 1983, los irreversibles (bloqueo tubárico y vasectomía). En 1985 se aprobó la Ley orgánica 9/1985, que despenalizó el aborto en tres supuestos y en 1988 se aprobó la primera Ley de Reproducción Asistida. La apertura legislativa continuó con la autorización de la comercialización de la píldora anticonceptiva de urgencia (2001) y su venta

${ }^{4}$ La pregunta remite al mes anterior cuando otras encuestas internacionales lo hacen a: la última relación sexual, al año anterior y/o a la primera relación sexual (UN, DESA, WCU2010).

5 Los únicos datos actualizados para Italia proceden de una encuesta financiada por los laboratorios Schering y de otra encuesta a universitarios (Dalla Zuanna et al, 2005). 
directa, sin receta médica, en las farmacias (2009). En marzo de 2010, se publicó en el BOE la nueva Ley de Salud Sexual y Reproductiva y de la Interrupción Voluntaria del Embarazo.

En este contexto, se realizaron diversas encuestas nacionales. Por un lado, las Encuestas de Fecundidad llevadas a cabo por el INE en 1977, 1985 y 1999 y la ya comentada Fertility and Family Survey (FFS) de 1995. Posteriormente, en 2003, el INE realizó la Encuesta de Salud y Hábitos Sexuales. El Centro de Investigaciones Sociológicas (CIS) realizó la Encuesta de Fecundidad y Valores (EFV) en 2006, la encuesta sobre Actitudes y Prácticas Sexuales en 2008, y en 2009 la Encuesta Nacional de Salud Sexual (ENSS).

Por otro lado, contamos con la encuesta nacional llevada a cabo por la Sociedad Española de Contracepción (SEC) y la Federación de Planificación Familiar de España (FPFE), patrocinadas por el laboratorio Bayer-Schering. Los resultados fueron publicados en el Libro blanco de la anticoncepción en España (SEC-FPFE-Schering, 2005) para el período que va desde 1997 hasta 2003. A partir de 2003 esta encuesta pasa a ser publicada por el equipo Daphne.

La siguiente tabla muestra la prevalencia anticonceptiva calculada para España por los diferentes organismos y equipos de investigación:

Tabla 2. Evolución de las prácticas anticonceptivas en España

\begin{tabular}{|c|c|c|c|c|c|c|c|c|c|c|}
\hline ESPAÑA & INE & INE & $\begin{array}{c}\text { CIS } \\
\text { FFS(a) }\end{array}$ & INE & $\begin{array}{l}\text { SEC- } \\
\text { FPFE- } \\
\text { Bayer }\end{array}$ & $\begin{array}{l}\text { CIS } \\
\text { (b) }\end{array}$ & $\begin{array}{l}\text { CIS } \\
\text { (c) }\end{array}$ & $\begin{array}{l}\text { DAP- } \\
\text { HNE }\end{array}$ & $\begin{array}{l}\text { CIS } \\
\text { (d) }\end{array}$ & $\begin{array}{l}\text { DAP- } \\
\text { HNE }\end{array}$ \\
\hline Año & 1977 & 1985 & 1995 & 1999 & 1999 & 2006 & 2006 & 2007 & 2009 & 2009 \\
\hline $\begin{array}{l}\text { Prevalencia } \\
\text { anticoncepción \% }\end{array}$ & $\mathbf{5 0 , 0}$ & 58,14 & 81,1 & 71,7 & 61,2 & 65,7 & 69,6 & $\mathbf{7 9 , 7}$ & 71,5 & 78,8 \\
\hline $\begin{array}{l}\text { Prev. métodos } \\
\text { modernos \% }\end{array}$ & 21,3 & 36,26 & 67,4 & 66 & 55,7 & 62,3 & 65,9 & $\mathbf{7 2 , 4}$ & 69,7 & $\mathbf{7 4 , 8}$ \\
\hline \multicolumn{11}{|l|}{ Esterilización } \\
\hline $\begin{array}{l}\text { - femenina } \\
\text { - masculina }\end{array}$ & $\begin{array}{l}2,6 \\
0,0\end{array}$ & $\begin{array}{l}2,9 \\
0,3\end{array}$ & $\begin{array}{r}12,1 \\
8,1\end{array}$ & $\begin{array}{r}10,1 \\
9\end{array}$ & $\begin{array}{l}4,5 \\
6,5\end{array}$ & $\begin{array}{l}5,6 \\
7,9\end{array}$ & $\begin{array}{l}4,62 \\
6,46\end{array}$ & 4,1 & $\begin{array}{l}3,7 \\
4,4\end{array}$ & $\begin{array}{l}4,3 \\
4,6\end{array}$ \\
\hline Píldora & 11,7 & 15,7 & 14,6 & 13,1 & 16,5 & 17,2 & 19,3 & 20,3 & 20,6 & 17,9 \\
\hline $\begin{array}{l}\text { Inyecciones o } \\
\text { Implantes }\end{array}$ & & - & 0,2 & 0,1 & - & 0,2 & 0,2 & - & - & - \\
\hline DIU & 0,5 & 5,7 & 7,6 & 6,6 & 5,9 & 6,4 & 5,6 & 4,5 & 4,2 & 4,9 \\
\hline Preservativo & 4,9 & 12,3 & 24,3 & 27,0 & 21,9 & 24,8 & 29,8 & 38,8 & 35,8 & 37,3 \\
\hline Barreras vaginales & 0,1 & - & 0,6 & 0,1 & - & 0,2 & 0,2 & - & 0,6 & - \\
\hline Otras & 1,5 & - & - & 0,0 & 0,4 & 0,0 & 0,0 & 4,7 & 0.4 & 5,7 \\
\hline
\end{tabular}




\begin{tabular}{lrrrrrrrrrrr}
\hline \multicolumn{1}{c}{ ESPANA } & INE & INE & $\begin{array}{c}\text { CIS } \\
\text { FFS(a) }\end{array}$ & $\begin{array}{r}\text { INE } \\
\text { Año }\end{array}$ & $\begin{array}{c}\text { SEC- } \\
\text { Bayer }\end{array}$ & $\begin{array}{c}\text { CIS } \\
\text { (b) }\end{array}$ & $\begin{array}{c}\text { CIS } \\
\text { (c) }\end{array}$ & $\begin{array}{c}\text { DAP- } \\
\text { HNE }\end{array}$ & $\begin{array}{c}\text { CIS } \\
\text { (d) }\end{array}$ & $\begin{array}{r}\text { DAP- } \\
\text { HNE }\end{array}$ \\
\hline $\begin{array}{l}\text { Prev. métodos } \\
\text { tradicionales \% }\end{array}$ & $\mathbf{3 1 , 4}$ & $\mathbf{2 0 , 1 2}$ & $\mathbf{1 3 , 6}$ & $\mathbf{5 , 7}$ & $\mathbf{5 , 0}$ & $\mathbf{3 , 5}$ & $\mathbf{3 , 4}$ & $\mathbf{3 , 0}$ & $\mathbf{5 , 7}$ & $\mathbf{2 , 8}$ \\
\hline Ritmo & 6,3 & 3,7 & 1,9 & 0,8 & 0,7 & 0,3 & 0,2 & 0,5 & - & 0,6 \\
\hline Coitus interruptus & 23,0 & 15,7 & 11,4 & 4,0 & 4,3 & 1,9 & 1,6 & 2,5 & 3,5 & 2,2 \\
\hline Otras & 2,1 & 2,1 & 0,3 & 0,9 & - & 1,3 & 1,6 & - & 2,2 & - \\
\hline Población & $15-49$ & $18-49$ & $20-49$ & $15-49$ & $15-49$ & $15-49$ & $15-49$ & $15-49$ & $16-49$ & $15-49$ \\
\hline $\mathrm{N}$ & 5.814 & 8.863 & 6.012 & 7.749 & 2.136 & 3.100 & 3.887 & 2.105 & 2.914 & 2.108 \\
\hline
\end{tabular}

Fuentes:

INE 1977: Encuesta de Fecundidad: metodología y resultados, INE, 1978:180. Mujeres casadas no embarazadas.

INE 1985: Encuesta de Fecundidad, INE, 1987:224, y, Ruiz Salguero, 2000:16. Mujeres casadas o en unión, no embarazadas.

INE 1999: www.un.org/esa/population/publications/contraceptive2007/contraceptive2007. htm

CIS-FFS 1995: World Contraceptive Use, 2011. http://www.unece.org/pau/ffs/ffstab.html

CIS 2006: World Contraceptive Use, 2011. a: 4812 mujeres sexualmente activas el mes anterior, no embarazadas y 1991 hombres; b: mujeres sexualmente activas con pareja estable conviviendo en el hogar; c: estudio CIS n. ${ }^{\circ} 2639$, incluye mujeres sin pareja conviviendo.

CIS 2009. Microdatos estudio CIS n. ${ }^{\circ} 2780$ d: muestra de mujeres de 16 a 49 años, métodos utilizados siempre o casi siempre con pareja estable en últimos 12 meses.

SEC-FPFE-Bayer-Schering y Daphne: http://www.equipodaphne.es/encuestas.php

La diferencia entre los datos aportados por las encuestas del equipo Daphne (años 1999 y 2007) y por el INE (1999) y el CIS (2006), es de 10 puntos porcentuales en el mismo año y en el transcurso de un sólo año, por lo que no se pueden atribuir fácilmente esos desajustes a la fecha de aplicación. Tampoco al rango de edad, dado que las citadas encuestas utilizan las convenciones establecidas por N.U. en cuanto a la edad fértil (15-49 años). En lo que sí hay diferencia es en la definición de la base poblacional: el CIS (2006) consulta a las mujeres sexualmente activas, con y sin pareja estable residiendo en el hogar; mientras que el INE (1999) y las encuestas Daphne consultan a todas las mujeres en edad fértil, independientemente de su actividad sexual o situación de convivencia.

Otro aspecto metodológico a considerar es el tamaño muestral, éste nos informa sobre los márgenes de error, y, por tanto, sobre la precisión de las esti- 
maciones. Según este criterio, los datos del INE y del CIS son más precisos que los del equipo Daphne. Pero, el tamaño muestral no es suficiente para explicar las grandes variaciones encontradas, como tampoco lo es el tipo de muestreo, siempre que sea probabilístico. Por tanto, para afinar los análisis, revisamos los objetivos de las encuestas, los cuestionarios: la formulación de las preguntas, los períodos de referencia, los filtros y las alternativas de respuesta, además del modo de aplicación del cuestionario. A continuación, exponemos los matices introducidos en las encuestas para, seguidamente, comparar e interpretar los resultados presentados en la tabla 2 .

\subsection{Las encuestas de Fecundidad del Instituto Nacional de Estadística (INE, 1977, 1985 y 1999).}

Las Encuestas de Fecundidad del INE no son idénticas en las diferentes aplicaciones. En 1977, aún prohibido el uso de anticonceptivos en España, se realizó la encuesta al amparo de la Encuesta Mundial de Fecundidad. El marco poblacional fueron las mujeres residentes, alguna vez casadas de entre 15 y 49 años y la muestra estuvo formada por 5.814. En 1985, ya despenalizados los anticonceptivos $^{6}$, la encuesta se realizó a todas las mujeres de 18 a 49 años, independientemente de su estado civil. La muestra real estuvo formada por 8.863 mujeres y la longitud del cuestionario se redujo (Aguinaga, 1989:9). En ambas encuestas se preguntó por el uso de anticonceptivos «en algún momento de su vida» y «en la actualidad», y, fue aplicada por encuestadoras. En 1999 se realiza la tercera Encuesta de Fecundidad del INE, siguiendo recomendaciones de N.U. Su principal objetivo fue obtener información sobre: las características demográficas de las mujeres en edad fértil (15 a 49 años), su entorno social y familiar y los factores que influyen en la fecundidad. En esta ocasión la muestra real fue de 7.749 mujeres residentes. El modo de aplicación del cuestionario fue con encuestador y con ayuda de ordenadores portátiles, posibilitando a las entrevistadas que lo desearon introducir ellas mismas sus datos en el ordenador. Ganar en confidencialidad y reducir el efecto legitimidad (o de deseabilidad social, conducente a la emisión de respuestas ajustadas a lo que se considera adecuado o deseable), serían las ventajas de esta modalidad de aplicación.

Las preguntas del cuestionario referían «la utilización de métodos anticonceptivos» a dos momentos del tiempo: «en algún momento de su vida» $\mathrm{y}$ «en la actualidad».

${ }^{6}$ El Real Decreto 2275/78 modificó los artículos del Código Penal, en los que se establecía que vender, prescribir, divulgar u ofrecer cualquier cosa destinada a evitar la procreación era delito (cf. Ruiz Salguero, 2000:7). 
«P64. Existen varios métodos para evitar o retardar el embarazo. De los que se enumeran indique cuál conoce, cuál ha utilizado y cuál utiliza en la actualidad (No procede contestar «utiliza actualmente» a la persona que está embarazada)

- Píldora

- DIU

- Diafragma, tapón o esponja vaginal

- Abstinencia

- Preservativo o condón

- Condón femenino

- Ritmo y temperatura basal

- Coitus interruptus

- Lavado vaginal

- Cremas anticonceptivas

- Lactancia prolongada

- Inyección

- Píldora del día siguiente

- Ligadura de trompas (esterilización femenina)

- Vasectomía (esterilización masculina)

- Otros métodos

Conoce Hautilizado $\begin{gathered}\text { Utiliza } \\ \text { actualmente }\end{gathered}$

$\begin{array}{cccccc}\text { Sí } & \text { No } & \text { Sí } & \text { No } & \text { Sí } & \text { No } \\ 1 & 2 & 1 & 1 & 1 & 2 \\ 1 & 2 & 1 & 2 & 1 & 2 \\ 1 & 2 & 1 & 2 & 1 & 2\end{array}$

$\begin{array}{llllll}1 & 2 & 1 & 2 & 1\end{array}$

$\begin{array}{llll}1 & 2 & 1 & 1\end{array}$

$\begin{array}{llllll}1 & 2 & 1 & 2 & 1 & 2\end{array}$

$\begin{array}{llllll}1 & 2 & 1 & 2 & 1 & 2\end{array}$

$\begin{array}{lllllll}1 & 2 & 1 & 2 & 1 & 2\end{array}$

$\begin{array}{lllllll}1 & 2 & 1 & 2 & 1 & 2\end{array}$

$\begin{array}{llllll}1 & 2 & 1 & 2 & 1 & 2\end{array}$

$\begin{array}{llllll}1 & 2 & 1 & 2 & 1 & 2\end{array}$

$\begin{array}{llllll}1 & 2 & 1 & 2 & 1 & 2\end{array}$

$\begin{array}{llllll}1 & 2 & 1 & 2 & 1 & 2\end{array}$

$\begin{array}{llllll}1 & 2 & 1 & 2 & 1 & 2\end{array}$

$\begin{array}{llllll}1 & 2 & 1 & 2 & 1 & 2\end{array}$

$\begin{array}{llllll}1 & 2 & 1 & 2 & 1 & 2\end{array}$

$\begin{array}{llllll}1 & 2 & 1 & 2 & 1\end{array}$

El enunciado de la pregunta considerada remite al momento actual. A esta variante se suma un nuevo elemento distorsionador, las categorías de respuesta: ofrecer «coitus interruptus» en vez de «marcha atrás o retirada» como alternativa, puede contribuir a una infravaloración del uso de este método, por ser un término demasiado técnico, no adaptado a la heterogeneidad poblacional. Según esta fuente la prevalencia del uso de anticonceptivos entre las mujeres españolas era, en 1999, del 71,7\% y, el uso del coitus interruptus descendía al $4 \%$.

EMPIRIA. Revista de Metodología de Ciencias Sociales. N. ${ }^{\circ}$ 25, enero-junio, 2013, pp. 93-120. ISSN: $1139-5737$ 


\subsection{La Encuesta de Salud y Hábitos Sexuales (INE, 2003)}

En 2003, el INE realizó la Encuesta de Salud y Hábitos Sexuales, con una muestra de 13.600 personas de 18 a 49 años. Se siguió un método mixto de administración del cuestionario: entrevista asistida por ordenador con entrevistador, y, auto-administrado. El objetivo fue conocer las conductas de riesgo respecto a las infecciones de transmisión sexual. Por ello realizan numerosas preguntas respecto al uso de preservativos: quién los aporta, quién y cómo informa; el consumo de alcohol y otras conductas de riesgo en relación con las prácticas sexuales. El estudio cuenta con un cuestionario general y tres específicos, dirigidos a: hombres con pareja heterosexual, hombres con pareja homosexual y mujeres. Sólo en el cuestionario de mujeres se formulan dos preguntas sobre el uso de anticonceptivos en la primera relación sexual:

«P31. ¿Tomaron precauciones para evitar el embarazo en esta primera relación sexual?

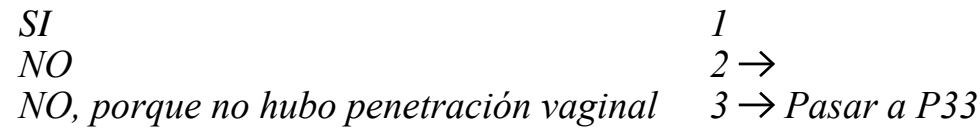

P32. ¿Cuáles de los siguientes métodos para evitar el embarazo usaron usted o su pareja? Puede señalar varias opciones.

Píldora

"Marcha atrás" o retirada

Píldora del día siguiente

"Ogino" (método del ritmo)

1

2

3

4

5

Otros métodos (cremas espermicidas, diafragma, DIU,

Vasectomía, ligadura de trompas

Nos sentíamos seguros porque fue durante la menstruación

En este caso, la pregunta remite a la primera relación sexual, admite el uso combinado de varios métodos y las alternativas de respuesta sin ser exhaustivas (faltan los nuevos métodos hormonales: parche, anillo...) son más claras. El problema aquí es que los resultados de la primera relación sexual (prevalencia anticonceptiva $69,5 \%$ y marcha atrás $15,2 \%$ ), no son comparables con aquellos referidos al momento de aplicación de la encuesta.

\subsection{La Encuesta de Fecundidad y Valores (EFV-CIS, 2006)}

En el 2006, el CIS realizó la EFV (estudio n ${ }^{\circ} 2639$ ) con el objetivo de estudiar los comportamientos reproductivos y su interrelación con los determinantes subyacentes, siguiendo las recomendaciones de N.U. El modo de aplicación 
fue con encuestadora. Para calcular la prevalencia anticonceptiva en España, se introducen las siguientes precisiones en la base poblacional: mujeres residentes, de entre 15 y 49 años, no embarazadas que tuvieron relaciones heterosexuales completas en las últimas cuatro semanas:

«P.508 ¿Ha utilizado usted y/o su pareja algún método anticonceptivo durante las últimas cuatro semanas?
Sí
No
N.C.

P.509 ¿Qué método de protección anticonceptiva, o combinación de métodos, ha utilizado Ud. o su pareja en las últimas cuatro semanas? (MOSTRAR TARJETA).

Esterilización de la entrevistada (ligadura de trompas)

Esterilización del hombre (vasectomía)

Píldoras, pastillas

DIU (dispositivo intrauterino)

Inyecciones

Preservativo

Píldora del día siguiente

Diafragma

Crema lespumas espermicidas/ esponjas

Abstinencia periódica $($ OGINO)

Retirada (coitus interruptus)

Cualquier otro método

N.C.

Obsérvese que se mantiene el enunciado de la pregunta utilizado en la FFS (CIS,1995) pero, se introducen variaciones en las alternativas de respuesta, aclarando el significado de los métodos expresados técnicamente en anteriores oleadas. Así el coitus interruptus pasa a ser: «retirada o coitus interruptus» (no «marcha atrás»), «píldoras o pastillas»... y, siguen sin incluirse los nuevos métodos. Ahora bien, estando más claras las alternativas de respuesta, la prevalencia anticonceptiva disminuye.

Este estudio distingue las mujeres sexualmente activas con pareja estable conviviendo en el hogar, de aquellas sin pareja estable en el hogar. Estas últimas constituyen una muestra mucho más pequeña (787 frente a 3.100), de la cual casi el $80 \%$ tienen menos de 30 años. La prevalencia anticonceptiva alcanza el $85 \%$ en este sub-grupo, siendo del $65,7 \%$ para las que conviven con una pareja estable. La media ponderada entre estos dos porcentajes es de $69,6 \%$. Por tanto, la prevalencia de uso de anticonceptivos para las mujeres sexualmente activas de 15 a 49 años era en 2006, en España, del 69,6\%, según esta fuente. Este dato sería el más comparable con el obtenido por el INE en 1999, dado que no limitaba la población diana a las casadas o en unión aunque tampoco lo hacía a las sexualmente activas. 


\subsection{La encuesta telefónica del CIS 2008: Actitudes y prácticas sexuales}

La encuesta telefónica: Actitudes y prácticas sexuales (estudio $\mathrm{n}^{\circ} 2738$ ) fue aplicada a una muestra de 1.500 personas, de ambos sexos y de 18 años y más. No nos detenemos en ella ni la incluimos en la tabla por dos razones:

1) el tamaño muestral: para comparar datos referidos a la población de 15 a 49 años, seleccionamos de la muestra de 18 años y más, a los menores de 50, quedando reducida a 881 casos. De estos, sólo 446 informaron sobre el tipo de anticonceptivo usado, con el aumento del margen de error que ello supone, y,

2) las variaciones introducidas en la formulación de la pregunta: desaparecen las referencias temporales y la actividad sexual se sustituye por la orientación sexual:

«P30. Solo si tiene pareja estable y no es homosexual. En la actualidad, cuando tiene usted relaciones sexuales con su pareja ¿utiliza usted algún método de prevención de embarazo?» Varias alternativas.

P31A. ¿Qué método/s anticonceptivo utiliza?

Píldoras

Preservativo

Píldora del día siguiente

Ogino

Marcha atrás o retirada (coitus interruptus)

Otros métodos

\subsection{La Encuesta Nacional de Salud Sexual (CIS-MSPS, 2009)}

La Encuesta Nacional de Salud Sexual (ENSS), fue realizada entre noviembre de 2008 y enero de 2009, por el CIS-MSPS (estudio n ${ }^{\circ} 2780$ ). Forma parte del Plan de Calidad del Sistema Nacional de Salud que contempla como objetivo realizar una encuesta para «generar conocimiento sobre la salud sexual en mujeres y hombres útil para identificar las necesidades de información y atención sanitaria existentes». La encuesta incluye a hombres y mujeres residentes en la muestra de 9.850 sujetos de 16 años y más. El modo de aplicación fue mixto: con personal encuestador, una parte y otra auto-administrada. La principal novedad de esta encuesta es que maneja el concepto de sexualidad expandida, en vez del tradicional de sexualidad coital ${ }^{7}$. El cuestionario pregunta por el método anticonceptivo utilizado en: la primera relación sexual, el último año con la pareja estable, y, la última relación esporádica. La encuesta va en la

${ }^{7}$ Se consideran relaciones sexuales el «conjunto de prácticas que realizan dos o más personas, de igual o diferente sexo, con la finalidad de obtener placer sexual, que no tiene por qué incluir el coito, ni concluir con el orgasmo». 
línea que probablemente acabe instalándose en Europa: incluir a los varones en las encuestas sobre salud sexual y reproductiva para avanzar así en la corresponsabilidad anticonceptiva.

Formulan a quienes han tenido relaciones sexuales sólo con su pareja estable en los últimos doce meses y han utilizado anticonceptivos, las siguientes preguntas:

«P37. ¿Con que frecuencia ha usado métodos anticonceptivos en las relaciones sexuales con su pareja estable en los últimos 12 meses?

Siempre 1 Casi siempre 2 Algunas veces 3 Casinunca 4 Nunca 5 etc. 6

No fue necesario por el tipo de práctica, estar en edad no fértil, ser estéril,

P37a. ¿Cuál o cuáles suele utilizar? (multirespuesta)

Píldora

Preservativo masculino

Preservativo femenino

Píldora del día siguiente

Marcha atrás o retirada (coitus interruptus)

Vasectomía

Ligadura de trompas

DIU

Otros métodos (cremas, espermicidas, diafragmas)

No Contesta

$\mathrm{Y}$, a quienes tuvieron relaciones con una pareja esporádica, les preguntan por el método utilizado en la última ocasión y les ofrecen las mismas opciones que en la p37a.

Los resultados de esta encuesta dependen de cómo interpretemos la frecuencia de uso (P37), si consideramos usuarios a los que han contestado «siempre o casi siempre», y acotamos al grupo de edad a 16-44 años, la prevalencia anticonceptiva referida por la muestra de mujeres sería de $73,7 \%$ y por los hombres algo inferior, 69,8\%. Si ampliamos el rango de edad a 16-49 años, la tasa desciende y el sentido por sexo se mantiene (71,5\% mujeres y $67,3 \%$ en hombres). Al analizar los datos por métodos debe tenerse en cuenta el período referido (año anterior, en las relaciones estables). Los resultados abundan en la hegemonía del preservativo masculino y la píldora en las relaciones estables y del preservativo en las relaciones esporádicas.

\subsection{Las encuestas del Equipo Daphne}

El Equipo Daphne está formado por profesionales de la ginecología y financiado por Bayer Schering Pharma. La encuesta de Anticoncepción entre las mujeres españolas se viene realizando desde 1997 pero las fichas técnicas 
son muy sucintas. En el Libro Blanco de la anticoncepción en España (2005), se comentan los resultados de las encuestas realizadas entre 1997 y 2003 por el equipo Daphne y se hacen algunas referencias al tipo de muestreo pero, ni presentan el cuestionario completo ni hacen más precisiones. En equipodaphne.es, la ficha técnica de la encuesta de 2007 informa sobre: el universo poblacional: mujeres en edad fértil, 15 a 49 años. Ámbito nacional. Muestra 2015 mujeres. Margen de error 1,56\%. Entrevista personal y tasa de respuesta 98,3\%.

En 2007, según esta fuente, el $80 \%$ de las mujeres en edad fértil utilizaban algún método anticonceptivo. En 2009, «se observa una estabilización en el uso de métodos después del progreso ascendente de la última década que nos ha ido acercando al perfil de nuestro entorno europeo. Los métodos más usados siguen siendo el preservativo (37\%) y la píldora (18\%), y se aprecia el despunte de nuevas opciones anticonceptivas como el «doble método» ${ }^{8}$ que alcanza el $1,5 \%$ [...]. El uso de métodos naturales, así como las esterilizaciones definitivas se estabilizan, y siguen creciendo tímidamente opciones como el DIU (4,9\%) y algo más las nuevas formas anticonceptivas hormonales como el parche o el anillo (5,7\%)» (Bayer Health Care, 2009).

Como estas encuestas periódicas no permiten conocer los enunciados de las preguntas (lo períodos de referencia, el requerimiento de uno a más métodos, el formato de las preguntas) y las fichas técnicas son muy escuetas o no son públicas, las posibilidades de interpretación de los resultados son muy limitadas.

\section{INTERPRETANDO LOS DATOS}

Las encuestas del Equipo Daphne aportan las tasas más elevadas después de la FFS. Según la encuesta más reciente, la cobertura anticonceptiva alcanzaría al $78,8 \%$ de la población, siete puntos porcentuales por encima de lo estimado por el CIS ese año y próxima a la aportada por la FFS en 1995. Sin embargo, en 1999 los datos Daphne estaban diez puntos por debajo de los del INE. Desconocemos si en este intervalo introdujeron cambios significativos en el diseño que expliquen esas variaciones. Así las cosas, en adelante, nos ceñimos a las últimas encuestas cuyas fichas metodológicas son completas, están disponibles y son comparables.

Otorgar mayor credibilidad al INE y al CIS, supone aceptar que el uso de anticonceptivos en España, no ha aumentado en los últimos años. La tendencia al alza, iniciada con la despenalización ${ }^{9}$, alcanzó el punto álgido en 1995

${ }^{8}$ Uso combinado del preservativo y un método hormonal (píldora, generalmente pero también DIU, implante ...). Práctica que se intenta imponer desde los laboratorios y algunas instancias oficiales para prevenir eficazmente tanto las ITS como los embarazos no deseados.

${ }^{9}$ Incremento discreto comparado con la apertura que vivió la sociedad española en esa década. «El aumento más significativo corresponde al preservativo, respondiendo a la campaña de prevención del SIDA. La píldora, en cambio no tuvo el aumento esperado tras la legalización» (Ruiz-Salguero,2000:15-16). 
$(81,1 \%)$ y, desde ahí descendió al 71,7\% de 1999 (explicable, en parte, por las diferencias introducidas en la acotación de la base poblacional) para continuar la tendencia bajista en 2006, y, recuperarse moderadamente en 2009, hasta alcanzar los niveles de la década anterior $(71,5 \%)$.

Mientras que los datos globales para Europa muestran un mantenimiento de la cobertura anticonceptiva, en España el punto culminante se produce en 1995 para iniciar en ese momento un descenso hasta estabilizarse alrededor del 71\% ¿Efecto del modo de construcción de los datos y/o tendencia? Probablemente, ambas cosas. Se confirma, nuevamente, que cada vez que se introduce una matización o cambio en el proceso de construcción de los datos, disminuye la precisión de las comparaciones y, en el ámbito analizado, los cambios son constantes. A partir de ahí, algunas tasas son explicables por esos cambios y otras no. En concreto, detectamos los siguientes efectos de las técnicas en los datos:

1) Definición de la base poblacional:

- Estado civil y situación de convivencia: cuando se admite cualquier situación de convivencia, la tasa aumenta y cuando se restringe a las casadas, la tasa disminuye (en las encuestas más recientes).

- Rango de edad: cuando se utiliza el rango completo 15-49, la tasa disminuye, y, cuando se excluye al grupo de más edad, la tasa aumenta.

- País de origen: consultar a la población residente en España disminuye ligeramente la tasa, frente a la población nacida en España ${ }^{10}$.

- Período de referencia: cuanto menor es el período de referencia, menor es la posibilidad de uso de cualquier método (en especial, los de uso esporádico) y cuanto mayor el período, mayores probabilidades de uso.

2) El sexo del informante es otro aspecto de la base poblacional que introduce variaciones significativas en el uso de anticonceptivos, en la ENSS (CIS,2009) ${ }^{11}$ :

Mujeres Hombres

P14a. la primera relación sexual

Píldora

Preservativo

P37a. a lo largo del año anterior con pareja estable

Píldora

Preservativo
$16,4 \%$

$81,5 \%$

$29,7 \%$

$52,7 \%$
$5,7 \%$

$90,2 \%$

10 Conclusiones ratificadas por los análisis realizados con los datos de la ENSS (CIS,2009). Diferencias significativas en prevalencia anticonceptiva por: estado civil, situación de convivencia, edad y país de origen.

11 Aunque Delgado y Castro (1998:73) al analizar los datos de la FFS encontraron que «las pautas de uso de anticonceptivos declaradas por los varones no diferían significativamente de las de las mujeres».

EMPIRIA. Revista de Metodología de Ciencias Sociales. N. ${ }^{\circ}$ 25, enero-junio, 2013, pp. 93-120. ISSN: 1139-5737 
Mujeres

P41a. última relación esporádica
$22,9 \%$

$85,2 \%$
Hombres

$$
\begin{array}{r}
7,5 \% \\
92,1 \%
\end{array}
$$

Las mujeres manifiestan un mayor uso de la píldora de lo reflejado por los varones pero, en el caso del preservativo ocurre lo contrario. Es decir, los hombres sostienen utilizar más el anticonceptivo masculino y las mujeres el femenino. El control sobre la ingesta de la píldora es femenino y, el conocimiento de los varones por este extremo limitado, sobre todo en las primeras relaciones y las esporádicas. Por tanto, consideramos el sexo del informante relevante para cuestiones relativas al uso de anticonceptivos; las mujeres aportarían información más precisa y matizada que los varones, aumentando ligeramente la prevalencia.

3) El modo de aplicación del cuestionario. Al enfrentarnos a un tema sensible $^{12}$, los informantes podrían contestar de forma poco consistente si percibieran que el modo de aplicación no garantiza la máxima confidencialidad de la información. El CIS en el informe metodológico de la ENSS sostiene que se «comprobó la utilidad de los cuestionarios auto-cumplimentados para conseguir una mayor sinceridad de las respuestas» (2009:7). Un análisis secundario de los datos muestra que el modo auto-administrado arroja, sistemáticamente, mayores tasas de uso de la marcha atrás pero, también del preservativo y la píldora. Resultados que cuestionan el efecto legitimidad generado por la presencia del encuestador (salvo en el caso de la marcha atrás) y que apuntan a un realización más pausada y atenta de los cuestionarios cara a cara (con encuestador). En esta dirección apuntan también las tasas de no respuesta parcial (considerando no sabe y no contesta), utilizadas como indicador de la calidad de la encuesta, pues nos orientan hacia la encuesta con encuestador-a ${ }^{13}$. Las encuestas españolas revisadas fueron realizadas por personal encuestador o con sistema mixto (encuestador-a / auto-administrado). En Francia, la aplicación de la FFS fue auto-administrada y obtuvo baja tasa de respuesta y el Barometré de Santé (datos

${ }^{12}$ El estudio $n^{\circ} 2676$, ratifica que los temas sobre los que más molesta contestar son: política, religión, hábitos sexuales e ingresos (CIS,2007a). Dillman et al (2009) puntualizan que el análisis de las preguntas sobre temas sensibles es útil para conocer el efecto de la deseabilidad social en cada modalidad de administración, y valorar las ventajas al respecto mostradas por la encuesta auto-administrada.

${ }^{13}$ La ENSS da la opción a los encuestados de rellenar personalmente dos partes de la encuesta en dos cuadernillos. Aquellos que optan por continuar con el encuestador-a presentan diferencias significativas con quienes optan por el auto-administrado, por edad y nivel de estudios, no así por sexo ni país de origen. Por tanto, revisamos las tasas de uso de anticonceptivos (píldora, preservativo, marcha atrás y total) en la primera relación sexual y en las relaciones estables, por modo de aplicación del cuestionario, controlando por nivel de estudios y por edad. Los cuestionarios auto-administrados registraron sistemáticamente mayores tasas de uso de anticonceptivos y de no respuesta parcial (NRP), que los realizados por encuestadores. No obstante, la mayor tasa de NRP fue la registrada por la encuesta telefónica del CIS, 2008.

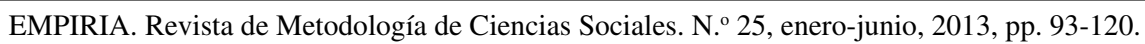
ISSN: $1139-5737$ 
reflejados en la tabla 2) fue una encuesta telefónica ${ }^{14}$. En suma, en las encuestas sobre anticoncepción, consideramos que los modos de aplicación auto-administrado y mixto (con encuestador / auto-administrado) contribuyen al aumento de la tasa, salvo en la FFS que fue con encuestador. Esta última modalidad se perfila como una de las más precisas, al contrario de las realizadas por teléfono.

4) El enunciado de la pregunta, aun inquiriendo por varios métodos anticonceptivos, afecta a la precisión en la captación de los métodos que se utilizan de forma esporádica, especialmente si el período de referencia es breve. Por otro lado, no tenemos garantías de que el análisis de las preguntas multirespuesta sea unívoco. Es más, en el análisis que de la FFS hacen Delgado y Castro, se especifica que «si utilizan varios métodos, sólo se refleja el método más efectivo» (Nota 4, tabla 4.3, 1998:71). Este matiz contribuye a explicar las bajas tasas de uso del coitus interruptus registradas en las encuestas. Sobre este método, la ENSS (2009) obtiene tasas de uso más elevadas, en tanto pregunta por un largo período de tiempo (el año anterior) y con la pareja estable: muestra de 16 años y más, de mujeres, 5,2\% y de hombres 6,0\%. Entre las mujeres de 16 a 49 años, la tasa es del 3,5\% y entre sus homólogos varones del 3,7\%.

5) El formato de respuesta: abierta o categorizada y, en el último caso, la adecuación terminológica. Sólo la FFS utilizó un formato de pregunta abierta y, para España, obtuvo la tasa más elevada de la historia anticonceptiva de este país. Lo que apunta a la obtención de respuestas más ajustadas a la norma con este formato. Pero, difícilmente podemos atribuir un efecto aislado al formato de la pregunta dado que ese rasgo va acompañado de otras variaciones en el diseño. Las demás encuestas utilizaron preguntas categorizadas, ofreciendo alternativas de respuesta cada vez más comprensibles. Aunque las alternativas siguen sin ser exhaustivas, sus significados son más claros y se muestran al informante.

Si revisamos las características técnicas de cada encuesta, así como su efecto creciente o decreciente en la tasa resultante, observamos que los diseños más adecuados para obtener altas tasas de prevalencia anticonceptiva son los de 1995, 2006b y 2009. Siendo las del INE 1999 y del CIS 2006, las menos proclives a ello. Lo que no significa que busquemos los diseños más adecuados para obtener una determinada tasa, sino que estamos analizando las fuentes de variación o efectos observados para de ahí, ganar en precisión al interpretar los resultados y al realizar nuevas mediciones del objeto de estudio. En este sentido, consideramos que ganaríamos en validez si consultáramos a las mujeres con

${ }^{14}$ En Bajos, Beltzer y Bozon (2008), se profundiza en cómo introducir mejoras en las encuestas telefónicas: repetir la llamada hasta 15 veces en caso de ausencia (para acceder a la población con más estudios, urbana, viviendo sola y extranjera). Completar la muestra de teléfonos fijos con una muestra de móviles. Dejar cierta autonomía a los encuestadores para el relanzamiento de las preguntas y prestarles asesoramiento y apoyo técnico y psicológico. Levinson (2008) observa que los encuestadores anticipan las estructuras de respuestas de los sujetos en función de la coherencia previa y de su posición social y que rara vez se estudian las interacciones entre la anticipación y la adaptación del estilo de intervención (tono de voz, velocidad, explicaciones adicionales...) (cf. Bajos y Bozon, 2008).

EMPIRIA. Revista de Metodología de Ciencias Sociales. N. ${ }^{\circ}$ 25, enero-junio, 2013, pp. 93-120. ISSN: $1139-5737$ 
necesidades anticonceptivas, independientemente de su estado civil, y evitáramos o refináramos las encuestas telefónicas ${ }^{15}$.

Tabla 3. Encuestas nacionales comparadas

\begin{tabular}{|c|c|c|c|c|c|c|c|c|}
\hline & Año & $\begin{array}{l}\text { Preva- } \\
\text { lencia }\end{array}$ & Universo & $\begin{array}{c}\text { Actividad } \\
\text { Sexual }\end{array}$ & $\begin{array}{l}\text { Período } \\
\text { referencia }\end{array}$ & $\begin{array}{c}\text { País } \\
\text { origen } \\
\text { (nacidas / } \\
\text { residentes }\end{array}$ & $\begin{array}{l}\text { Modo } \\
\text { de aplica- } \\
\text { ción }\end{array}$ & Fuente \\
\hline INE & 1977 & $50 \%$ & $\begin{array}{l}\text { Mujeres } \\
\text { alguna vez } \\
\text { casadas, } \\
15-49 \text { años }\end{array}$ & $\begin{array}{l}\text { Con y sin } \\
\text { actividad } \\
\text { sexual }\end{array}$ & $\begin{array}{l}\text { En la ac- } \\
\text { tualidad / } \\
\text { En algún } \\
\text { momento }\end{array}$ & Residentes & $\begin{array}{l}\text { Con en- } \\
\text { cuestadora }\end{array}$ & $\begin{array}{l}\text { INE, 1978, } \\
\text { Encuesta de } \\
\text { Fecundidad: } \\
\text { metodología y } \\
\text { resultados, Ma- } \\
\text { drid, Ministerio } \\
\text { de Economía. }\end{array}$ \\
\hline INE & 1985 & $58 \%$ & $\begin{array}{l}\text { Mujeres de } \\
18-49 \text { años, } \\
\text { indepen- } \\
\text { dientemen- } \\
\text { te del esta- } \\
\text { do civil }\end{array}$ & $\begin{array}{l}\text { Con y sin } \\
\text { actividad } \\
\text { sexual }\end{array}$ & $\begin{array}{l}\text { En la ac- } \\
\text { tualidad / } \\
\text { en algún } \\
\text { momento }\end{array}$ & Residentes & $\begin{array}{l}\text { Con en- } \\
\text { cuestadora }\end{array}$ & $\begin{array}{l}\text { INE, 1987, } \\
\text { Encuesta de Fe- } \\
\text { cundidad } 1985 . \\
\text { Madrid. } \\
\text { RUIZ SALGUE- } \\
\text { RO, M (2000) }\end{array}$ \\
\hline $\begin{array}{l}\text { FFS- } \\
\text { CIS }\end{array}$ & 1995 & $81,1 \%$ & $\begin{array}{l}\text { Ambos } \\
\text { sexos. Ca- } \\
\text { sados y no } \\
\text { casados, } \\
20-49\end{array}$ & $\begin{array}{l}\text { Sexual- } \\
\text { mente } \\
\text { activas }\end{array}$ & $\begin{array}{l}4 \text { semana } \\
\text { previas }\end{array}$ & Españoles & $\begin{array}{l}\text { Con en- } \\
\text { cuestador- } \\
\text { a del mis- } \\
\text { mo sexo q } \\
\text { encuesta- } \\
\text { do-a }\end{array}$ & $\begin{array}{l}\text { UN, World Con- } \\
\text { traceptive Use, } \\
2011 \\
\text { UNECE, http:// } \\
\text { www.unece.org/ } \\
\text { pau/ffs/ffstab. } \\
\text { html }\end{array}$ \\
\hline INE & 1999 & $71,7 \%$ & $\begin{array}{l}\text { Mujeres } \\
\text { casadas y } \\
\text { no casadas, } \\
15-49\end{array}$ & $\begin{array}{l}\text { Con y sin } \\
\text { actividad } \\
\text { sexual }\end{array}$ & $\begin{array}{l}\text { En la ac- } \\
\text { tualidad }\end{array}$ & Residentes & $\begin{array}{l}\text { Mixto:con } \\
\text { encues- } \\
\text { tador y } \\
\text { ordenador } \\
\text { portátil }\end{array}$ & $\begin{array}{l}\text { UN, World Con- } \\
\text { traceptive Use, } \\
2007 \\
\text { INE, 1999, En- } \\
\text { cuesta de Fecun- } \\
\text { didad (EF). }\end{array}$ \\
\hline $\begin{array}{l}\text { INE } \\
\text { MSC }\end{array}$ & 2003 & $\begin{array}{l}\text { PRS } \\
69,5 \%\end{array}$ & $\begin{array}{l}\text { Ambos se- } \\
\text { xos } 18 \text { a } 49 \\
\text { años. Inde- } \\
\text { pendiente- } \\
\text { mente es- } \\
\text { tado civil / } \\
\text { orientación } \\
\text { sexual }\end{array}$ & $\begin{array}{l}\text { Primera } \\
\text { relación } \\
\text { sexual }\end{array}$ & $\begin{array}{l}\text { Primera } \\
\text { Relación } \\
\text { Sexual }\end{array}$ & Residentes & $\begin{array}{l}\text { Mixto: } \\
\text { entrevista } \\
\text { asistida por } \\
\text { ordenador } \\
\text { con entre- } \\
\text { vistador y } \\
\text { auto-admi- } \\
\text { nistrado }\end{array}$ & $\begin{array}{l}\text { INE- MSC, } \\
\text { 2003, Encuesta } \\
\text { de Salud y Há- } \\
\text { bitos Sexuales } \\
\text { (ESHS). }\end{array}$ \\
\hline
\end{tabular}

15 El CIS (2007b) informa del mayor cinismo en las repuestas telefónicas que en las encuestas cara a cara. Además de que hay sectores de la población más accesibles a cada modalidad. Chang y Krosnick (2009) señalan que «la encuesta telefónica presenta un mayor error de medida, un mayor efecto complacencia (survey satisficing) y un mayor número de respuestas socialmente deseables (cf. Díaz de Rada, 2011:53). 


\begin{tabular}{|c|c|c|c|c|c|c|c|c|}
\hline & Año & $\begin{array}{l}\text { Preva- } \\
\text { lencia }\end{array}$ & Universo & $\begin{array}{c}\text { Actividad } \\
\text { Sexual }\end{array}$ & $\begin{array}{l}\text { Período } \\
\text { referencia }\end{array}$ & $\begin{array}{c}\text { País } \\
\text { origen } \\
\text { (nacidas / } \\
\text { residentes }\end{array}$ & $\begin{array}{l}\text { Modo } \\
\text { de aplica- } \\
\text { ción }\end{array}$ & Fuente \\
\hline CIS & 2006 & $65,7 \%$ & $\begin{array}{l}\text { Mujeres } \\
\text { casadas o } \\
\text { en unión, } \\
\text { con pareja } \\
\text { estable en } \\
\text { el hogar, } \\
15-49\end{array}$ & $\begin{array}{l}\text { Sexual- } \\
\text { mente } \\
\text { activas }\end{array}$ & $\begin{array}{l}4 \text { sema- } \\
\text { nas pre- } \\
\text { vias }\end{array}$ & Residentes & $\begin{array}{l}\text { Con en- } \\
\text { cuestado- } \\
\text { ras en el } \\
\text { domicilio }\end{array}$ & $\begin{array}{l}\text { - U.N. WCU, } \\
2011\end{array}$ \\
\hline CIS & 2006 & $69,6 \%$ & $\begin{array}{l}\text { Mujeres } \\
\text { con y sin } \\
\text { pareja } \\
\text { estable en } \\
\text { el hogar, } \\
15-49\end{array}$ & Activas & $\begin{array}{l}4 \text { sema- } \\
\text { nas pre- } \\
\text { vias }\end{array}$ & Residentes & $\begin{array}{l}\text { Con en- } \\
\text { cuestado- } \\
\text { ras en el } \\
\text { domicilio }\end{array}$ & $\begin{array}{l}\text { - Estudio no } \\
\text { 2639, CIS. } \\
\text { - DELGADO, } \\
\text { M (2007) En- } \\
\text { cuesta de fecun- } \\
\text { didad, familia y } \\
\text { valores, Opinio- } \\
\text { nes y Actitudes, } \\
\text { 59, CIS }\end{array}$ \\
\hline CIS & 2008 & $70,5 \%$ & $\begin{array}{l}\text { Con pareja, } \\
\text { no homo- } \\
\text { sexuales. } \\
\text { Ambos } \\
\text { sexos } 18 \text { y } \\
\text { más años } \\
\text { (tasa: } 18- \\
49 \text { ) }\end{array}$ & $\begin{array}{l}\text { Activos } \\
\text { aunque } \\
\text { sea es- } \\
\text { porádica } \\
\text { mente }\end{array}$ & $\begin{array}{l}\text { Sin espe- } \\
\text { cificar }\end{array}$ & Residentes & $\begin{array}{l}\text { Entrevista } \\
\text { telefónica }\end{array}$ & $\begin{array}{l}\text { - Microdatos } \\
\text { Estudio n }{ }^{\circ} 2738 \text {, } \\
\text { CIS. }\end{array}$ \\
\hline $\begin{array}{l}\text { CIS- } \\
\text { MS } \\
\text { PS }\end{array}$ & 2009 & $71,5 \%$ & $\begin{array}{l}\text { Con rela- } \\
\text { ciones en } \\
\text { el último } \\
\text { año. Am- } \\
\text { bos sexos, } \\
16 \text { años y } \\
\text { más (tasa: } \\
\text { muje- } \\
\text { res,16-49) }\end{array}$ & $\begin{array}{l}\text { Activas- } \\
\text { os (año } \\
\text { anterior) }\end{array}$ & $\begin{array}{l}\text { Año } \\
\text { de refe- } \\
\text { rencia / } \\
\text { Primera } \\
\text { Relación } \\
\text { Sexual }\end{array}$ & Residentes & $\begin{array}{l}\text { Mixto: } \\
\text { con en- } \\
\text { cuestador / } \\
\text { auto-admi- } \\
\text { nistrado }\end{array}$ & $\begin{array}{l}\text { - Microdatos } \\
\text { Estudio no } 2780 \text {, } \\
\text { CIS. } \\
\text { CIS-MINISTE- } \\
\text { RIO DE SANI- } \\
\text { DAD Y POLÍ- } \\
\text { TICA SOCIAL } \\
\text { (2010), Estrate- } \\
\text { gia Nacional de } \\
\text { Salud Sexual, } \\
\text { Sanidad, } 2010 .\end{array}$ \\
\hline
\end{tabular}

\section{DE LA TÉCNICA DE ENCUESTA A LAS TÉCNICAS CUALITATIVAS: EL CASO DE LA «MARCHA ATRÁS»}

Veíamos que Italia era el mayor usuario del coitus interruptus y que aún continúan publicándose investigaciones que pretenden explicarlo, acuñando para Italia la expresión: «sociedad anticonceptiva imperfecta» (Gribaldo, Judd y 
Kertzer, 2009). Estos autores, recurren a la metodología cualitativa y resuelven que «los hombres y las mujeres usan métodos tradicionales para organizar su reproducción de forma socialmente aceptable» $(2009: 577)^{16}$. Las concepciones del honor y la respetabilidad contribuyen a que la marcha atrás sea considerada un elemento de distinción y autocontrol en un contexto en que el deseo puede ser domesticado ${ }^{17}$. Así, los elementos de respetabilidad, disciplina y control se combinan con las nociones de naturalidad, espontaneidad y destino en los discursos sobre prácticas anticonceptivas. En la línea de lo establecido por Dalla Zuanna, De Rose y Racioppi (2005), Gribaldo et al., insisten en que el recurso a la marcha atrás en Italia es favorecido por: 1) el papel de la iglesia católica, 2) las desigualdades del sistema de género, 3 ) la cultura médica que limita la prescripción de la píldora (2005:21) y, en general, las recomendaciones emanadas de los sistemas de salud que orientan las decisiones anticonceptivas (Gribaldo et al., 2009:558).

Volviendo a España, los datos cuantitativos muestran que el descenso de la prevalencia de la marcha atrás ha sido muy pronunciado, pasando del $23 \%$ en 1977 al 15,7\% en 1985 (tras la despenalización) y al 11,4\% en 1995. El gran salto numérico se observa en la encuesta del INE de 1999, donde el $4 \%$ de las mujeres utilizarían este método tradicional, descendiendo al 1,9\% de las mujeres sexualmente activas, en 2006. Ese año, la marcha atrás era «usado por respectivamente el $1,9 \%$ y el $0,4 \%$ de las mujeres conviviendo con su pareja en el hogar y sin ella, alcanzando al 3,7\% de las mujeres de 45-49 años con pareja estable. El coito interrumpido para las menores de 25 años representa el tercer método, estas junto con las de 45-49 años son los dos grupos de edad que más utilizan este método» (Delgado et al, 2007:120). Esta encuesta aporta datos por comunidades autónomas, la prevalencia de la marcha atrás era del 2,8\% en Andalucía (CIS, 2006). Por otro lado, veíamos que la ENSS (CIS, 2009) apuntaba al 3,5\% de las mujeres y al 3,7\% de los varones (de 16 a 49 años) usuarios de la marcha atrás con la pareja estable durante el año de referencia, aumentando al $9,1 \%$ y $7 \%$ cuando se pregunta por la primera relación sexual, a los de todas las edades.

Ahora bien, ¿qué información adicional obtendremos a través de las técnicas cualitativas? Contamos con nueva información cualitativa para Andalucía, donde el recurso a la marcha atrás está muy presente entre los informantes que participaron en la investigación en 2009-2010. En ella entrevistamos en profundidad a 22 personas, distribuidas del siguiente modo: 8 menores de 21 años ( 5 chicas y 3 chicos), 8 mujeres de entre 26 y 36 años y 6 mujeres de 21 a 46 años con alguna discapacidad física o sensorial. La información producida a través de las entrevistas se complementa con la lograda a través de los 9

${ }^{16}$ Realizaron 349 entrevistas en profundidad en cuatro regiones italianas, en 2005-06. El estudio forma parte de un proyecto más amplio titulado: «Explaining Low Fertility in Italy» (ELFI), dirigido por : Kertzer, White, Bernardi y Barbagli.

17 «Prevenir los embarazos es sólo uno de los objetivos sociales del uso de métodos anticonceptivos» (cf. Gribaldo, Judd y Kertzer, 2009: 553). 
Grupos de Discusión realizados. Como criterios de segmentación de la muestra manejamos, además del sexo y la edad, la posición social, el tipo de hábitat y el tipo de discapacidad ${ }^{18}$. Tras el análisis sociológico de sus discursos, podemos afirmar que la «marcha atrás» es un recurso aún vigente entre los informantes, utilizado de forma esporádica con la pareja estable a cualquier edad, tanto en la clase baja rural y urbana como en la clase media urbana. Su uso continuado se ciñe a relaciones y situaciones muy concretas.

La marcha atrás es un método tradicional al que se recurre cuando la relación se estabiliza mínimamente, quedando excluida de los encuentros fortuitos con desconocidos. No suele ser un método prevalente por lo que el hecho de que no se utilizara en las últimas cuatro semanas no es infrecuente pero, no significa que no se utilice. Sospechamos que el descenso registrado en las encuestas, responde en parte a esta dinámica de uso ${ }^{19}$. Lo que sí ha aumentado es el conocimiento sobre la eficacia de los métodos y los riesgos del recurso a la marcha atrás. Los discursos de las mujeres adultas insisten en sus inconvenientes al tiempo que relatan sus experiencias y las de sus familiares:

«M5: Mis padres supuestamente hacían la marcha atrás y somos seis hermanos.

M1: la marcha atrás mismo ¿quién no ha hecho aquí la marcha atrás alguna vez? (ríe).

M5: Yo mi marido empezaba: parece que me he corrido un poquito dentro, se me ha salido, no estoy seguro... Digo: no, aquí no hay marcha atrás nunca más.

M2: para eso mi marido es...vaya...(todas hablan).

M1: yo vengo de una marcha atrás, de un chispeo [mis padres usaban] preservativo en la pandilla y una vez que hicieron la marcha atrás, aquí estoy yo.

M4: Es que es eso, mi suegra le pasó lo mismo» (GD5:17, Mujeres, 30-33 años, clase baja urbana).

En otro lugar, analizamos las trayectorias anticonceptivas de los informantes y observamos que, generalmente, se usan preservativos en las primeras relaciones sexuales para ir prescindiendo de ellos cuando la relación se estabiliza ${ }^{20}$. Entonces, o bien se combina el uso del condón con la «marcha atrás» o bien se cambia a la píldora, en función de la edad, la estabilidad de la relación y la incorporación de la lógica preventiva. La «marcha atrás» posee una fuerte carga simbólica (confianza, consolidación de la relación y triunfo del placer), además facilita la

${ }^{18}$ Las mujeres con discapacidad forman parte de la población general y, además, conforman una submuestra consultada con objetivos específicos en el contexto de la investigación.

${ }_{19}$ En ocasiones, a través de encuesta, se intentan captar las dinámicas: discontinuidades, segmentos de uso y cambios de métodos anticonceptivos.

${ }^{20}$ Los datos de uso de la marcha atrás de la ENSS (CIS, 2009) por grupos de edad, relativos a la primera relación sexual y al año de referencia, ratifican esta tendencia hasta los 35 años, a partir de esa edad la tendencia se invierte $y$, el recurso a la marcha atrás pasa a ser inferior durante el año anterior que en los primeros encuentros sexuales. 
espontaneidad y aumenta la excitación. Por ello sigue vigente ese método tradicional: tanto los chicos como las chicas refieren la práctica de la marcha atrás ${ }^{21}$. Los chicos ya sean estudiantes de formación profesional del medio rural,

«H2: las chicas, el «marrón» es para ellas, pero es más fácil hacerlo sin condón

H3: marcha atrás [...]

H2: porque tú no lo piensas en el momento, lo haces pero luego cuando te apalancas el domingo, lo piensas, te preocupas, luego te viene toda nerviosa... te chilla... malo» (GD3:17, chicos, 16 a 18 años, clase baja rural).

o universitarios urbanos, relatan experiencias con la marcha atrás aunque sus lógicas argumentales difieran:

«HF: por el placer de lo prohibido ¿no? De hacer lo que no se debe, igual que los que toman drogas, igual que te tomas algo. O sea ¿por qué lo haces?, porque no se debe, ¿por qué follas sin condón?, porque está prohibido. O sea, porque realmente sé que me arriesgo, y el riesgo me gusta. Disfruto de hacer el coito interruptus para no dejar embarazada a la chica... como que tienes que estar atento y eso te excita más ¿no?

HG: yo creo que el riesgo excita a muchas, a mucha gente le excita...» (GD4: 20, mixto universitarios, clase media, 22 a 27 años).

Las chicas, jóvenes y mayores, también relatan experiencias y juegos con la marcha atrás. Menos habitual es el recurso a esta práctica de forma continuada: bien por placer (confianza y compenetración con la pareja), bien por miedo a los posibles efectos secundarios de la píldora ${ }^{22}$, está práctica sólo la refieren grupos específicos. Entre nuestros informantes, el hábito de la marcha atrás lo relatan, por un lado, mujeres liberales y/o envueltas en relaciones poco igualitarias y, por otro lado, aquellas mujeres con acceso limitado a la información $\mathrm{y}$, generalmente, excluidas de las investigaciones (se expresan en lengua de signos) $)^{23}$ :

«T: pues nosotros ya llevamos 17 años con la marcha atrás, y sabemos controlar, a mí me ha ido bien... y lo hablamos antes y nos ponemos de acuerdo y bien, ahora si hay un fallo pues que le vamos hacer...

${ }^{21}$ Contamos con diferentes investigaciones cualitativas desarrolladas en España. En CIMOP (2005) se «observa cierta "relajación" en la "norma" discursiva que prescribe utilizar "siempre" el preservativo en el marco de una relación sexual que pueda conllevar algún riesgo» (cf. MSC, $2008: 35-37)$.

${ }^{22}$ «M: una persona empieza a tomar la pastilla anticonceptiva, y ya cuando se casa y quiere tener un hijo de tanto tomarse la pastilla ya le cuesta más quedarse embarazada, que a una le pasó que en un año solo le vino la regla 2 veces, a mí eso me parece imposible...Yo es que me da mucho miedo la pastilla, prefiero no tomármela, prefiero usar condón o marcha atrás» (GD7:2 mujeres 27 a 33 años, clase media urbana, con discapacidad auditiva).

${ }^{23}$ Las personas con discapacidad presentan las mismas necesidades anticonceptivas que las demás (Kaplan, 2006). Aunque, la comunicación sobre sexualidad es especialmente difícil para 
C: pues yo igual que ella, sabemos frenar [...]

T: no, pero el mío nunca usa condón, siempre es la marcha atrás, así llevamos mucho tiempo, el condón no, que eso quema... (risas)

C: claro, ella no lo usa porque no le da placer, no quiere usar condón por eso» (GD6:4, mujeres, 33-43 años, clase baja, con discapacidad auditiva).

Otrora, situaciones como el «calentón» que reclaman soluciones inmediatas, contribuyen a la extensión del uso de la marcha atrás en situaciones esporádicas. Sólo tras algunos sustos (y, en ocasiones, la ingesta de la píldora anticonceptiva de urgencia) ${ }^{24}$ o un mayor compromiso entre la pareja se realiza el tránsito del preservativo (en combinación o no con la marcha atrás) a la píldora. Ya en la edad adulta, los descansos de la píldora (en caso de parejas estables), los olvidos y descuidos en su ingesta y los encuentros íntimos inesperados con conocidos, configuran las situaciones más comunes en que las mujeres mantienen relaciones sexuales sin cobertura anticonceptiva moderna.

«Se usa mucho, mucho... que todavía hay mucha gente que usa la marcha atrás... porque la verdad que el preservativo cuando tú tienes una pareja estable y ya has mantenido relaciones con ella sin preservativo... luego volver... a lo bueno se acostumbra uno muy fácil... (risas) pero de lo bueno a lo malo cuesta más trabajo... Y, la verdad, el preservativo está muy bien pero para el que no sepa lo que es otra cosa [...] pero, cuando sabes lo que es hacerlo a pelo... pues hacerlo con preservativo como que...» (E14: 4, Mujer, 33 años, clase baja urbana).

Las lógicas que presiden estos tránsitos están protagonizadas por la confianza: confianza en que el chico «controla y se sabe salir a tiempo» y confianza en la fidelidad de la pareja, lo que ahuyenta la amenaza de infecciones. Confianza, fidelidad, placer, espontaneidad... contribuyen a explicar la vigencia de la tradicional «marcha atrás», desde una visión romántica de la sexualidad.

\section{LA ADECUACIÓN DE LAS TÉCNICAS AL OBJETO}

La discrepancia entre los datos cuantitativos y los discursos se debe tanto a las características del objeto de estudio como de los instrumentos. El objeto de estudio es un objeto íntimo y personal, además de cambiante. Las encuestas sobre prácticas anticonceptivas intentan medir una realidad dinámica, que cambia con la edad, con el tipo y la duración de la relación, con los encuen-

aquellas con discapacidad auditiva porque la lengua de signos utiliza formas concretas y precisas, sin circunloquios, que pueden resultar demasiado bruscas (Delaporte, 2002).

${ }^{24}$ De hecho, en todos los grupos de discusión hay referencias al uso de la marcha atrás y, de las 20 entrevistas a mujeres: seis sostienen haber practicado ese método, dos de ellas cómo método habitual con alguna de sus parejas (E6 y E8) y, siete recurrieron alguna vez a la píldora de urgencia (todas menos una de las usuarias de la marcha atrás y otras dos). 
tros esporádicos, con el estado de salud, con los nacimientos, separaciones y divorcios, con la situación de embriaguez, euforia... Realidad poco estable que no cumple las condiciones de las clases de equivalencia (Martín Criado, 2000), mostrándose reacia a la medición. Probablemente, el método utilizado de forma más inconsistente sea la marcha atrás; su uso suele ser esporádico y en combinación con otros métodos. Una dificultad añadida, destacada por Merlié (1993:119), radica en que «sólo los métodos medicalizados y modernos, para una parte al menos de las mujeres entrevistadas, parecía que merecían el nombre de anticonceptivos, tendiendo las que utilizaban métodos más tradicionales a no declararse como usuarias de un método anticonceptivo».

El instrumento analizado es la encuesta. La noción de anticoncepción es equívoca y los resultados están condicionados por la formulación de las preguntas y las definiciones manejadas. El diseño de la encuesta: base poblacional (mujeres con o sin pareja estable, con y/o sin actividad sexual en un período concreto de tiempo, con diferentes rangos de edad, sólo mujeres o también hombres, nacionales o residentes); la formulación de las preguntas (solicitando información sobre uno o varios métodos y refiriendo su uso a períodos de tiempo muy diferentes: la primera vez, alguna vez, la actualidad, las cuatro últimas semanas, el último año...), la terminología empleada y el efecto legitimidad, provocado por la situación de encuesta, contribuyen a explicar la discrepancia entre las tasas. De modo que las preguntas formuladas al inicio de este escrito obtienen respuesta al detectar el origen de las disimilaridades y discrepancias: incluir tanto a casadas como solteras, aumenta la tasa (aunque N.U. limita la población a las casadas o en unión, incluye en sus tablas datos obtenidos incluyendo a las solteras, con una nota explicativa) y excluir a las mayores de 44 reduce la tasa (táctica seguida por varios países incluidos en la tabla1, contra las recomendaciones de N.U). Mientras los datos utilizados por N.U. para España (CIS, 2006) respetan escrupulosamente los requisitos del modelo, países como Noruega y EE.UU. emplean estrategias que contribuyen al aumento de la prevalencia. El análisis comparativo revela, por tanto, que las distancias en prevalencia entre países son más discretas de lo que parecen.

Las diferencias entre la información cuantitativa y cualitativa se centran en el tipo y la calidad de la información. Contamos con una buena aproximación a la prevalencia anticonceptiva global y por métodos de uso continuado. La dificultad estriba en medir las prácticas poco estables y, el recurso a la marcha atrás suele serlo. Se usa preservativo y, en situaciones concretas, la marcha atrás, o, se usa la píldora y, ante descansos u olvidos, la marcha atrás. Esta práctica (como el uso inconsistente del preservativo o los olvidos de la píldora) rara vez es captada por las encuestas y, sin embargo, es central para comprender el recurso a la píldora de urgencia y las tasas de interrupción voluntaria del embarazo (IVEs). 


\section{BIBLIOGRAFÍA}

AGUINAGA, J. (1989): «Descenso de la fecundidad y modernización en la sociedad española: Análisis comparativo de las Encuestas de Fecundidad 1977 y 1985», Revista de Demografía Histórica, Vol. 7, n. ${ }^{\circ}$ 3, pp 7-22.

BAJOS, N. y BOZON, M. (eds) (2008) : Enquête sur la sexualité en France. Pratiques, Genre et Santé, La Découverte, Paris.

BAYER HEALTH CARE (2009) : Notas de prensa. Disponible en:

http://www.prensabayer.com/ebbsc/cms/es/Noticias_home/news_000628.html [consulta 2-3-2012]

CENTRO DE INVESTIGACIONES SOCIOLÓGICAS (CIS)

- (2006): Estudio n. ${ }^{\circ}$ 2639. Fecundidad y valores en la España del siglo XXI. Madrid.

- (2007a): Estudio n. ${ }^{\circ}$ 2676. Percepción social de las encuestas.

- (2007b): Boletín informativo. La encuesta a encuesta.

- (2008): Estudio n. ${ }^{\circ}$ 2738. Actitudes y practicas sexuales.

CIS y MINISTERIO DE SANIDAD Y POLÍTICA SOCIAL, (2009) : Estudio n. ${ }^{\circ}$ 2780, Encuesta Nacional de Salud Sexual.

DALLA ZUANNA, G.; DE ROSE, A. y RACIOPI, F. (2005): «Low fertility and limited diffusion of modern contraception in Italy during de second half of the twentieth century», Journal of Population Research, vol 22, n. ${ }^{\circ} 1$, pp. 21-48.

DELAPORTE, Y. (2002) : Les sourds cest comme ça, Paris, Editions de la Maison des Sciences de l'homme.

DELGADO, M. y CASTRO MARTÍN, T. (1998): Encuesta de fecundidad y familia 1995 (FFS), Opiniones y Actitudes n. ${ }^{\circ}$ 20, Madrid, CIS.

DELGADO, M. (Coord.), (2007): Encuesta de fecundidad, familia y valores, Opiniones y Actitudes, n. ${ }^{\circ}$ 59, Madrid, CIS.

DÍAZ DE RADA, V. (2010): «Eficacia de las encuestas por Internet: un estudio preliminar», Revista Española de Sociología, n. ${ }^{\circ}$ 13, pp. 4-79.

- (2011): «Encuestas con encuestador y auto-administradas por internet. ¿Proporcionan resultados comparables?, Revista Española de Investigaciones Sosciológicas, n. ${ }^{\circ} 136$, pp. $49-90$.

DILLMAN, Don A. et al (2009): «Response Rate and Measurement Differences in Mixed-mode Surveys Using Mail, Telephone, Interactive Voice Response (IVR) and the Internet», Social Science Research, n. ${ }^{\circ} 38$ (1), pp. 1-18.

EQUIPO DAPHNE, Encuestas sobre uso de anticonceptivos. Disponibles en: http:// www.equipodaphne.es/encuestas.php [consula 13-2-2012]

GÓMEZ BUENO, C. (dir) BRETIN, H. y PUENTE NAVAS, R. (2011a): Anticoncepción en Andalucía. I- Representaciones, discursos y prácticas profesionales, C.S. Junta de Andalucía, disponible en http://hdl.handle.net/10481/17742 [consulta 132-2012]

GÓMEZ BUENO, C. (dir) BRETIN, H; PUENTE NAVAS, R. et al. (2011b): Anticoncepción en Andalucía. II- Representaciones, discursos y prácticas de adolescentes y adultas, con y sin discapacidad. C.S. Junta de Andalucía, disponible en http://hdl. handle.net/10481/17743 [consulta 13-2-2012]

GRIBALDO, A; JUDD, M y KERTZER, D. I. (2009): «An Imperfect Contraceptive Society: Fertility and Contraception in Italy», Population and Development Review, 35, 3, pp. 551-584. 


\section{INSTITUTO NACIONAL DE ESTADÍSTICA (INE)}

- (1978): Encuesta de Fecundidad: metodología y resultados, Madrid, $\mathrm{M}^{\circ}$ de Economía.

- (1987): Encuesta de Fecundidad 1985, tomo I, Madrid, INE.

- (1999): Encuesta de Fecundidad.

INE Y MINISTERIO DE SANIDAD Y CONSUMO, (2003), Encuesta de Salud y Hábitos Sexuales.

INSTITUT NATIONAL DE PRÉVENTION ET D'ÉDUCATION POUR LA SANTÉ. Disponible en http://www.inpes.sante.fr/ [consulta 13-2-2012].

KAPLAN, C. (2006): «Special Issues in Contraception: Caring for Women With Disabilities », J Midwifery Womens Health, 51, pp. 450-456.

MARTÍN CRIADO, E. (2000): «El paro juvenil no es el problema, la formación no es la solución». En CACHÓN, Lorenzo Juventudes, mercados de trabajo y políticas de empleo, Zimig, Valencia.

MERLIÉ, D. (1993): «La construcción estadística». En: CHAMPAGNE, P. et al. Iniciación a la práctica sociológica, México, s XXI, pp. 103-163.

MINISTERIO DE SANIDAD Y CONSUMO (2008): La interrupción voluntaria del embarazo y los métodos anticonceptivos en jóvenes. Disponible en:

http://www.msc.es/organizacion/sns/planCalidadSNS/pdf/equidad/intVoluntariaJoven. pdf

MINISTERIO DE SANIDAD Y POLÍTICA SOCIAL (2010): Estrategia Nacional de Salud Sexual, Sanidad, 2010. Disponible en:

http://www.msps.es/organizacion/sns/planCalidadSNS/pdf/equidad/ENSSR.pdf

RUIZ-SALGUERO, M. (2000): «La anticoncepción en España según la encuesta de fecundidad y familia de 1995», XXII Simposi de la Societat Catalana de Contracepció.

Acte organitzat per l'Acadèmia de Ciències Mèdiques de Catalunya i de Baleares i per la Societat Catalana de Contracepció. Centre d'Estudis Demogràfics.

SOCIEDAD ESPAÑOLA DE CONTRACEPCIÓN (SEC) - Federación de Planificación Familiar de España-Bayer-Schering (2005): Libro blanco de la anticoncepción en España, Madrid, Aula Médica Ediciones.

UNITED NATIONS, Department of Economic and Social Affairs, Population Division (2011): World Contraceptive Use 2011. Disponible en:

http://www.un.org/esa/population/publications/contraceptive2011/contraceptive2011. htm [consulta 13-9-2012].

UNITED NATIONS ECONOMIC COMISSION FOR EUEROPE, Fertility and Family Survey. Disponible en: http://www.unece.org/pau/ffs/ffstab.html [consulta 13-9-2012]. 